\title{
Relationship of Circulating C5a and Complement Factor H Levels With Disease Control in Pregnant Women With Asthma
}

\author{
Anikó Bohács MD PhD, András Bikov MD PhD, István Ivancsó MD, Ibolya Czaller MD, \\ Renáta Böcskei MD, Veronika Müller MD, János Rigó Jr MD DSc, György Losonczy MD DSc, \\ and Lilla Tamási MD
}

\begin{abstract}
BACKGROUND: Asthma often complicates pregnancy and represents a risk of serious pregnancy complications. The complement system contributes to asthma pathogenesis and is up-regulated in healthy gestation as well. The anaphylatoxin C5a has a major pro-inflammatory role, and the complement factor $\mathrm{H}$ is a main soluble regulator protein both in asthma and during pregnancy; however, peripheral levels of these complement factors and their relationship to disease control have not yet been evaluated in pregnant subjects with asthma. METHODS: The present study aimed to investigate circulating $\mathrm{C5a}$ and complement factor $\mathrm{H}$ levels in asthma (non-pregnant subjects with asthma; $n=19$ ) and in pregnancy with asthma (pregnant subjects with asthma; $n=22)$, compared with healthy non-pregnant $(n=21)$ and healthy pregnant women $(n=13)$ and to test their relationship to clinical parameters of asthma (lung function, airway inflammation, and symptoms). RESULTS: Circulating C5a levels were higher in the pregnant asthma subject group compared with the healthy non-pregnant, healthy pregnant, and non-pregnant asthma groups: median 2.629 (interquartile range [IQR] $2.257-3.052) \mathrm{ng} / \mathrm{mL}$ versus 1.84 (IQR 1.576-2.563), 1.783 (IQR 0.6064-2.786), and 2.024 (IQR 1.232-2.615) $\mathrm{ng} / \mathrm{mL}$, respectively $(P=.02$ in all cases). C5a correlated negatively with $\mathrm{FEV}_{1}(\mathrm{r}=-0.44, P=.039)$ and $\mathrm{FVC}$ values $(\mathrm{r}=-0.64, P=.001)$ in the pregnant asthma group and positively with fraction of exhaled nitric oxide levels in the nonpregnant asthma group $(n=12, \mathrm{r}=0.78, P=.004)$. Complement factor $\mathrm{H}$ levels were elevated in both the healthy pregnant and pregnant asthma subject groups compared with the healthy non-pregnant group (median 1,082 [IQR 734.9-1,224] and 910.7 [IQR 614.5-1076] $\mu \mathrm{g} / \mathrm{mL}$ vs 559.7 [IQR 388.7$783.1] \mu \mathrm{g} / \mathrm{mL}, P=.002$ and $P=.004$, respectively) but not in the pregnant asthma group compared with the non-pregnant asthma group (median 687.4 [IQR 441.6-947.6] $\mu \mathrm{g} / \mathrm{mL}, P=.10$ ). CONCLUSIONS: Asthma during pregnancy increases the circulating level of pro-inflammatory C5a, which is accompanied by impaired lung function and partly counteracted by the gestation-specific elevation of regulatory complement factor $\mathrm{H}$ level (detected in pregnancy both in healthy and subjects with asthma). Key words: asthma; pregnancy; complement; C5a; complement factor H; biomarker. [Respir Care 2016;61(4):502-509. (C) 2016 Daedalus Enterprises]
\end{abstract}

\section{Introduction}

Asthma is a chronic inflammatory disease of the airways characterized by variable and recurring symptoms,

\footnotetext{
Drs Bohács, Bikov, Ivancsó, Czaller, Böcskei, Müller, Losonczy, and Tamási are affiliated with the Department of Pulmonology, Semmelweis University, Budapest, Hungary. Dr Rigó is affiliated with the 1st Department of Obstetrics and Gynecology, Semmelweis University, Budapest, Hungary.
}

This study was supported by Hungarian Respiratory Society grants to heightened local inflammation, and reversible air flow obstruction. It imposes a high burden of morbidity, especially if not controlled, which occurs in up to $50 \%$ of cases worldwide. ${ }^{1}$ At the same time, asthma is one of the most common chronic diseases complicating pregnancy, occurring in $8-12 \%$ of all gestations. ${ }^{2}$ It represents a risk of

\footnotetext{
Renáta Böcskei and András Bikov and by the Bolyai János Scholarship of Hungarian Academy of Sciences to Lilla Tamási. The authors have disclosed no conflicts of interest.
} 
potentially serious maternal and fetal morbidities, including preterm delivery, gestational hypertension, preeclampsia, low birthweight, and neonatal mortality.,4 In addition, pregnancy may also influence asthma control with the deterioration of symptoms in one third of all pregnant women with asthma. ${ }^{5}$ Notably, if the disease is well controlled, the risks of poor pregnancy outcomes decrease ${ }^{6}$; therefore, maintaining optimal control in this period is crucial. Hence, it would be especially important to understand the immune interactions between asthma and gestation and to have a more detailed view into inflammatory processes of asthma during pregnancy. Furthermore, because pregnancy itself can influence spirometry results, ${ }^{7}$ and because most of the available techniques used to determine asthma airway inflammation (eg, induced sputum) are semi-invasive and therefore cannot be used in pregnancy, circulating, non-invasively obtainable biomarkers related to asthma control could help in identifying pregnant women with asthma with elevated risk. However, to date, objective circulating markers reflecting asthma control are not known. Previously, we investigated 2 promising blood markers, but both of them proved to be helpful in asthma alone rather than in asthma during pregnancy. ${ }^{8,9}$

The complement system is an ancient danger-sensing component of innate immunity. Its functions include recognizing and eliminating microorganisms, immune complexes, and apoptotic cells, and it has a regulatory role influencing both innate and adaptive immunity. ${ }^{10} \mathrm{It}$ can be activated through the so-called classical, alternative, and lectin pathways. The complement system participates in the pathogenesis of asthma on several levels. ${ }^{11,12}$ An interesting element of this complex system is the fragment $\mathrm{C} 5 \mathrm{a}$, because it has a dual role in allergic inflammation. On one hand, it protects against Th2-mediated airway inflammation in the initial phase of sensitization by modulating dendritic cells, but on the other hand, it enhances airway inflammation and hyperreactivity in already established disease. ${ }^{11,12}$ In the latter case, it behaves as a major pro-inflammatory mediator by promoting chemotaxis and activation of many cell types, which results in release of cytokines, increased vascular permeability, and smooth muscle contraction. Elevated C5a levels were measured not only in bronchoalveolar lavage fluid ${ }^{13}$ and induced sputum of subjects with asthma, ${ }^{14}$ but also in their plasma ${ }^{15}$; moreover, plasma levels correlated with asthma severity. ${ }^{15}$

\footnotetext{
Correspondence: Lilla Tamási MD med. habil., Department of Pulmonology, Semmelweis University, Diós árok u. 1/c, 1125 Budapest, Hungary. E-mail: tamasi.lilla@med.semmelweis-univ.hu.
}

DOI: $10.4187 /$ respcare.04339

\section{QUICK LOOK}

\section{Current knowledge}

Asthma management during pregnancy can be difficult, and asthma that is not well controlled represents a risk of potentially serious maternal and fetal morbidities. The complement system participates in the pathogenesis of asthma and is involved in healthy pregnancy as well, but excess activation leads to pregnancy complications.

\section{What this paper contributes to our knowledge}

Plasma C5a levels were increased in pregnant women with asthma, and higher levels implied worse lung function. Plasma C5a levels were also associated with airway inflammation in non-pregnant subjects with asthma. A pregnancy-specific elevation of plasma complement factor $\mathrm{H}$ levels were observed in pregnant subjects regardless of concomitant asthma.

Complement factor $\mathrm{H}$ is one of the soluble inhibitor molecules that regulate complement activation, and it is a major alternative pathway regulator. Imbalances in complement factor $\mathrm{H}$ and its regulatory role contribute to tissue injury and can result in autoimmune diseases. ${ }^{16}$ In our earlier study, ${ }^{17}$ we found increased sputum (but not circulating) complement factor $\mathrm{H}$ concentration in subjects with asthma, which correlated with asthma control but not with plasma complement factor $\mathrm{H}$.

Normal human pregnancy is characterized by an upregulated complement system but at the same time by an immune tolerance. Thus, excess complement activation leads to pregnancy complications. Both $\mathrm{C} 5 \mathrm{a}^{18}$ and complement factor $\mathrm{H}^{19}$ levels were found to be higher in healthy pregnancy than in non-pregnant controls, but plasma C5a levels were further elevated in spontaneous abortion ${ }^{20}$ and preeclampsia. ${ }^{21,22}$ However, to date, data on circulating $\mathrm{C} 5 \mathrm{a}$ and complement factor $\mathrm{H}$ levels and their possible relationship to disease control are scarce in asthma and lacking for pregnant women with asthma.

Therefore, the present study aimed to investigate circulating $\mathrm{C} 5 \mathrm{a}$ and complement factor $\mathrm{H}$ levels in nonpregnant and pregnant subjects with asthma. Furthermore, to determine the utility of $\mathrm{C} 5 \mathrm{a}$ and complement factor $\mathrm{H}$ as a help in the evaluation of asthma control in pregnant subjects with asthma, we also investigated their relationship to major asthma control determinants (lung function parameters, airway inflammation, and symptoms). 


\section{C5a and Complement Factor H With Asthma Control in Pregnancy}

\section{Methods}

\section{Ethics Statement}

Written informed consent was obtained from the subjects, and our study was reviewed and approved by an independent ethics committee of the institution (Institutional and Regional Research Ethics Committee of Semmelweis Medical University). The study adhered to the tenets of the most recent revision of the Declaration of Helsinki.

\section{Study Participants}

The study had a cross-sectional design. Nineteen nonpregnant subjects with asthma, 22 pregnant subjects with asthma, 21 healthy non-pregnant subjects, and 13 healthy pregnant subjects were enrolled. Subjects with asthma were assessed at their regular visit at the out-patient clinic of the Department of Pulmonology, Semmelweis University. They had persistent disease, and asthma had been diagnosed according to the current guidelines ${ }^{1}$ at least 6 months before enrollment. Exclusion criteria were current smoking or $>5$ pack-years of smoking history, any other chronic disease (except for allergic rhinitis), acute infection within 4 weeks of measurement, fetal infection, and multi-fetal gestation. There were no complications in the 2 pregnant groups. Subjects were asked not to use their medication $12 \mathrm{~h}$ before visits. Healthy pregnant subjects were recruited when attending their scheduled visit at the first Department of Obstetrics and Gynecology, Semmelweis University. Healthy non-pregnant controls were volunteers and had a negative history and negative asthma status upon detailed physical and routine laboratory examination.

\section{Measurement of Serum C5a and Complement Factor H Levels}

Venous blood samples were collected in EDTA tubes and were processed within $2 \mathrm{~h}$. Plasma was separated and stored at $-80^{\circ} \mathrm{C}$ until analyses. The plasma levels of $\mathrm{C} 5 \mathrm{a}$ (Quidel, San Diego, CA) and complement factor H (Hycult, Uden, Netherlands) were determined with ELISA kits in the same samples.

\section{Lung Function, Fraction of Exhaled Nitric Oxide Measurements, and Asthma Control Evaluation}

Lung function was measured by means of an electronic spirometer (PDD-301/s, Piston, Budapest, Hungary) according to the American Thoracic Society guidelines. ${ }^{23}$ Three technically acceptable maneuvers were performed, and the best was used. $\mathrm{FEV}_{1}$, forced $\mathrm{FVC}$, peak expiratory flow, and airway resistance were recorded in subjects with asthma (non-pregnant subjects with asthma, $n=17$; pregnant subjects with asthma, $n=20$ ).

Airway inflammation was assessed with the fraction of exhaled nitric oxide $\left(\mathrm{F}_{\mathrm{ENO}}\right)$, which was measured with a NIOX MINO airway inflammation monitor (Aerocrine AB, Solna, Sweden) according to the European Respiratory Society/American Thoracic Society recommendations ${ }^{24}$ in 12 non-pregnant subjects with asthma and 18 pregnant subjects with asthma.

Asthma control was assessed using the Asthma Control Test (non-pregnant subjects with asthma, $n=16$; pregnant subjects with asthma, $n=20$ ) recommended by the current asthma guideline. ${ }^{1}$

\section{Statistics}

Data distribution was analyzed by the D'Agostino-Pearson normality test. Comparisons between the study groups were made with the Mann-Whitney, Kruskal-Wallis, and Dunn post hoc multiple comparison tests. Correlation analyses were performed using the Spearman test due to nonnormal distribution of data. Area under the curve values of receiver operating characteristic curves were calculated using standard methods, and data are presented as area under the curve receiver operating characteristics (95\% CI). $P$ values of $<.05$ were considered significant. The tests used were 2-tailed. Statistics were calculated using GraphPad Prism 5 (GraphPad Software, La Jolla, California). Data are expressed as median (interquartile range $[\mathrm{IQR}])$.

\section{Results}

\section{Clinical Characteristics}

Clinical data and inflammatory parameters of the 4 study groups are summarized in Table 1. The median age of participants in the 4 groups was comparable. Gestational age at blood sampling and at delivery or fetal birthweight did not differ between the pregnant subjects with asthma and healthy pregnant subject groups. The median (IQR) gestational age was 26.5 (17.75-33.25) and 24 (20.25-25) weeks in the pregnant subjects with asthma and healthy pregnant subject group, respectively. Every healthy pregnant woman was in the second trimester, whereas $41 \%$ of the pregnant women with asthma were in the third trimester. None of the subjects who were pregnant showed any obstetric complications. No difference was detected in the severity or control of asthma or in the $\mathrm{F}_{\mathrm{ENO}}$ levels between the non-pregnant and pregnant asthma groups (Table 1). Daily dose of inhaled corticosteroids (ICS) showed a trend to be higher in the non-pregnant asthma subject group than in the pregnant asthma subject group (median 400 [IQR 400-800] $\mu \mathrm{g}$ vs 300 [IQR 0-500] $\mu \mathrm{g}$ of 


\section{C5a and Complement Factor H With Asthma Control in Pregnancy}

Table 1. Clinical Data in the 4 Study Groups

\begin{tabular}{|c|c|c|c|c|c|c|c|}
\hline \multirow{2}{*}{ Parameters } & \multirow{2}{*}{$\begin{array}{l}\text { HNP }(n=21) \\
\text { Median (IQR) }\end{array}$} & \multicolumn{2}{|l|}{$\mathrm{HP}(n=13)$} & \multicolumn{2}{|c|}{ ANP $(n=19)$} & \multicolumn{2}{|l|}{$\mathrm{AP}(n=22)$} \\
\hline & & Median (IQR) & $n$ & Median (IQR) & $n$ & Median (IQR) & $n$ \\
\hline Age, y & $29(26.25-33.25)$ & $33(28.5-36)$ & & $35(26-37)$ & & $31.5(26.5-35)$ & \\
\hline Gestational age at sampling, wks & & $24(20.25-25)$ & & & & $26.5(17.75-33.25)$ & \\
\hline 2nd/3rd trimester, $n$ & & & $13 / 0$ & & & & $13 / 9$ \\
\hline Gestational age at delivery, wks & & $39(39-40)$ & 11 & & & $40(38-41)$ & 16 \\
\hline Fetal birth weight, $g$ & & $3,600(3,228-3,715)$ & 12 & & & $3,415(3,029-4,030)$ & 20 \\
\hline $\mathrm{FEV}_{1}, \mathrm{~L}$ & & & & $3.01(2.57-3.37)$ & 17 & $2.87(2.76-3.18)$ & 20 \\
\hline $\mathrm{FEV}_{1}, \%$ predicted & & & & $98(85-107)$ & 17 & $92(85-99.25)$ & 20 \\
\hline $\mathrm{FVC}, \mathrm{L}$ & & & & $3.94(3.43-4.205)$ & 17 & $3.82(3.3-4.165)$ & 20 \\
\hline FVC, $\%$ predicted & & & & $108(96.5-116)$ & 17 & $102.5(96.25-111.5$ & \\
\hline $\mathrm{PEF}, \mathrm{L} / \mathrm{s}$ & & & & $5.92(5.25-7.185)$ & 17 & $6.31(5.56-6.815)$ & 20 \\
\hline PEF, \% predicted & & & & $81(74.5-101.5)$ & 17 & $84(76.75-93)$ & 20 \\
\hline $\mathrm{R}_{\mathrm{aw}}, \%$ predicted & & & & $123(105.5-154)$ & 17 & $115(82-136)$ & 20 \\
\hline ACT total score & & & & $20(15.5-24)$ & 16 & $20.5(13-23.5)$ & 20 \\
\hline $\mathrm{F}_{\mathrm{ENO}}, \mathrm{ppb}$ & & & & $19(10.5-22)$ & 12 & $19(14.25-39)$ & 18 \\
\hline $\begin{array}{l}\text { Daily dose of ICS, } \mu \mathrm{g} \text { of } \\
\text { beclomethasone equivalent }\end{array}$ & & & & $400(400-800)$ & 17 & $300(0-500)$ & \\
\hline $\begin{array}{l}\text { Steroid-naive/steroid-treated } \\
\quad \text { subjects, } n\end{array}$ & & & & & $2 / 15$ & & $10 / 12$ \\
\hline $\begin{array}{l}\mathrm{HNP}=\text { healthy non-pregnant } \\
\mathrm{HP}=\text { healthy pregnant } \\
\text { ANP = asthma, non-pregnant } \\
\mathrm{AP}=\text { asthma, pregnant } \\
\mathrm{IQR}=\text { interquartile range } \\
\mathrm{PEF} \text { = peak expiratory flow } \\
\mathrm{R}_{\mathrm{aw}}=\text { airway resistance } \\
\mathrm{ACT} \text { = Asthma Control Test } \\
\mathrm{F}_{\mathrm{ENO}}=\text { fraction of exhaled nitric oxide } \\
\mathrm{ICS} \text { = inhaled corticosteroid }\end{array}$ & & & & & & & \\
\hline
\end{tabular}

beclomethasone equivalent, respectively, $P=.067$; Table 1). Fifteen non-pregnant and 12 pregnant subjects with asthma received ICS treatment. The median (IQR) Asthma Control Test total scores of 20 (15.5-24) in the non-pregnant asthma subject group and 20.5 (13-23.5) in the pregnant asthma subject group showed similar levels of disease control.

\section{Comparison of Circulating C5a and Complement Factor H Levels Among the 4 Groups}

Asthma itself did not influence peripheral C5a and complement factor $\mathrm{H}$ levels, because they were similar in the healthy non-pregnant subject and non-pregnant asthma subject groups (median 1.84 [IQR 1.576-2.563] ng/mL vs 2.024 [IQR 1.232-2.615] ng/mL C5a, respectively, $P=.98$, and 559.7 [IQR 388.7-783.1] $\mu \mathrm{g} / \mathrm{mL}$ vs 687.4 [IQR 441.6947.6] $\mu \mathrm{g} / \mathrm{mL}$ complement factor $\mathrm{H}$, respectively, $P=.30$; Fig. 1, A and B). Median (IQR) C5a levels were markedly higher in the pregnant asthma subject group (2.629 [2.257$3.052] \mathrm{ng} / \mathrm{mL}$ ) compared with the healthy non-pregnant subject $(1.84[1.576-2.563] \mathrm{ng} / \mathrm{mL}, P=.02)$, healthy pregnant subject $(1.783[0.6064-2.786] \mathrm{ng} / \mathrm{mL}, P=.02)$, and non-pregnant asthma subject groups (2.024 [1.232-2.615] $\mathrm{ng} / \mathrm{mL}, P=.02$; Fig. 1A). On the other hand, both healthy pregnancy and pregnancy in subjects with asthma were associated with elevation in complement factor $\mathrm{H}$ levels compared with the healthy non-pregnant subject group (1,082 [IQR 734.9-1,224] and 910.7 [IQR 614.5-1,076] $\mu \mathrm{g} / \mathrm{mL}$ vs 559.7 [IQR 388.7-783.1] $\mu \mathrm{g} / \mathrm{mL}, P=.002$ and $P=.004$, respectively), whereas complement factor $\mathrm{H}$ levels were elevated only in the healthy pregnant group $(P=.03)$ and not in the pregnant asthma subject group $(P=.10)$ when compared with the non-pregnant asthma subject group (687.4 [IQR 441.6-947.6] $\mu \mathrm{g} / \mathrm{mL}$; Fig. 1B). The complement factor $\mathrm{H}$ levels did not differ between the healthy pregnant subject and pregnant asthma subject groups $(P=.29$; Fig. 1B). The 2 complement factors correlated with each other only in the healthy non-pregnant subject group $(\mathrm{r}=0.5, P=.02)$.

\section{Relationship of C5a and Complement Factor $\mathrm{H}$ to Asthma Control Determinants}

Pointing to the possible relationship between complement activation and airway inflammation, there was a sig- 

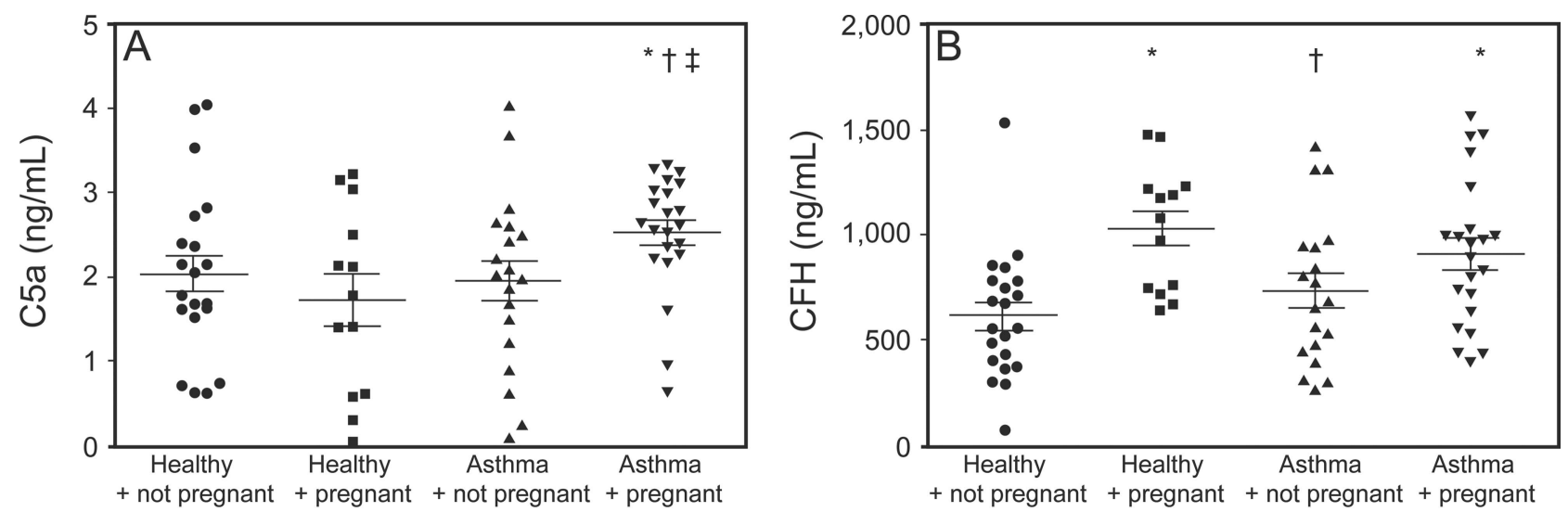

Fig. 1. Median (interquartile range) circulating $\mathrm{C} 5 \mathrm{a}(\mathrm{A})$ and complement factor $\mathrm{H}(\mathrm{CFH})(\mathrm{B})$ levels measured in non-pregnant and pregnant healthy subjects and in non-pregnant and pregnant subjects with asthma; C5a, 1.84 (1.576-2.563), 1.783 (0.6064-2.786), 2.024 (1.2322.615), and $2.629(2.257-3.052) \mathrm{ng} / \mathrm{mL}$, respectively; complement factor $\mathrm{H}, 559.7$ (388.7-783.1), 1,082 (734.9-1,224), 687.4 (441.6-947.6), and $910.7(614.5-1,076) \mu \mathrm{g} / \mathrm{mL}$, respectively. ${ }^{*} P<.05$ versus healthy + non-pregnant subjects. $\dagger P<.05$ versus healthy pregnant subjects. $\ddagger P<.05$ versus asthma + non-pregnant subjects.

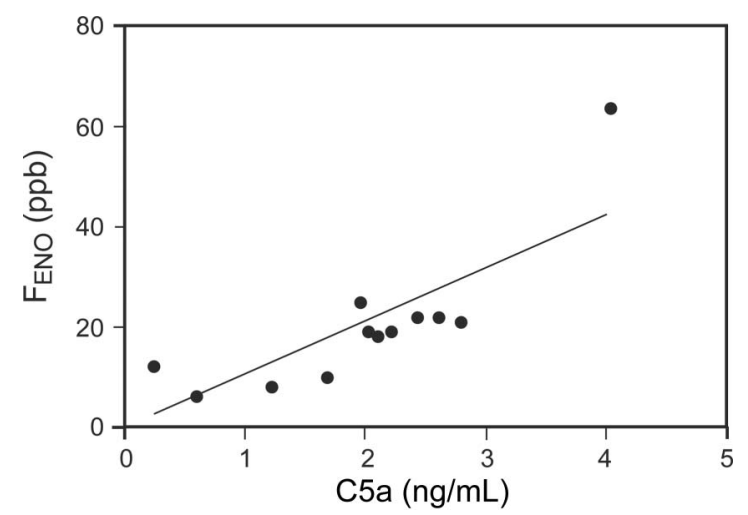

Fig. 2. Positive correlation between circulating $\mathrm{C} 5 \mathrm{a}$ and fraction of exhaled nitric oxide $\left(F_{E N O}\right)$ levels in non-pregnant subjects with asthma $(n=12)$.

nificant positive correlation between $\mathrm{C} 5 \mathrm{a}$ and $\mathrm{F}_{\mathrm{ENO}}$ levels $(n=12, \mathrm{r}=0.78, P=.004$; Fig. 2$)$ in the non-pregnant asthma subject group. Furthermore, in the pregnant asthma subject group, C5a levels correlated negatively with $\mathrm{FEV}_{1}$ $(\mathrm{r}=-0.44, P=.039 ;$ Fig. $3 \mathrm{~A})$ and $\mathrm{FVC}$ values $(\mathrm{r}=-0.64$, $P=.001$; Fig. 3B).

To obtain a more detailed view on the interactions of asthma air flow obstruction and inflammation, the relationship of complement factor $\mathrm{H}$ levels with lung function was also examined. However, a trend toward a correlation between complement factor $\mathrm{H}$ levels and peak expiratory flow values $(n=11 ; \mathrm{r}=0.61, P=.052)$ could be observed only in the subgroup of pregnant subjects with asthma in the second trimester and not in the whole pregnant asthma subject cohort $(P>.05)$. We did not find further correlations between the complement factors and any of the remaining lung function parameters or Asthma Control Test total scores.
Age of the participants did not influence the level of the 2 complement factors in any of the groups. The prescribed dose of the ICS was not related to either complement level.

\section{ROC Analysis of C5a and Complement Factor H Levels in Controlled and Uncontrolled Asthma}

In order to evaluate the possible utility of C5a and complement factor $\mathrm{H}$ measurements in the detection of uncontrolled asthma, ROC analyses of C5a and complement factor $\mathrm{H}$ levels were performed in subgroups of pregnant and non-pregnant subjects with asthma with peak expiratory flow above and below $80 \%$ and Asthma Control Test total score above and below 20, because the current GINA guideline suggests these cut-off values to differentiate between optimal and suboptimal asthma control. ${ }^{1}$ We did not find any significant effect of the 2 proteins in the detection of suboptimal asthma control.

\section{Relationship of Complement Factors and Functional Parameters to Obstetric Data}

$\mathrm{C} 5 \mathrm{a}$ and complement factor $\mathrm{H}$ concentrations were not related to gestational age at sampling in the pregnant asthma subject nor in the healthy pregnant subject group. There was no difference between C5a or complement factor $\mathrm{H}$ values of pregnant women with asthma in the second versus the third trimester.

We could not detect any association between C5a or complement factor $\mathrm{H}$ levels and obstetric data, such as gestational age at delivery and fetal birthweight. In the healthy pregnant group, women carrying female fetuses had slightly higher complement factor $\mathrm{H}$ levels compared 


\section{C5a and Complement Factor H With Asthma Control in Pregnancy}
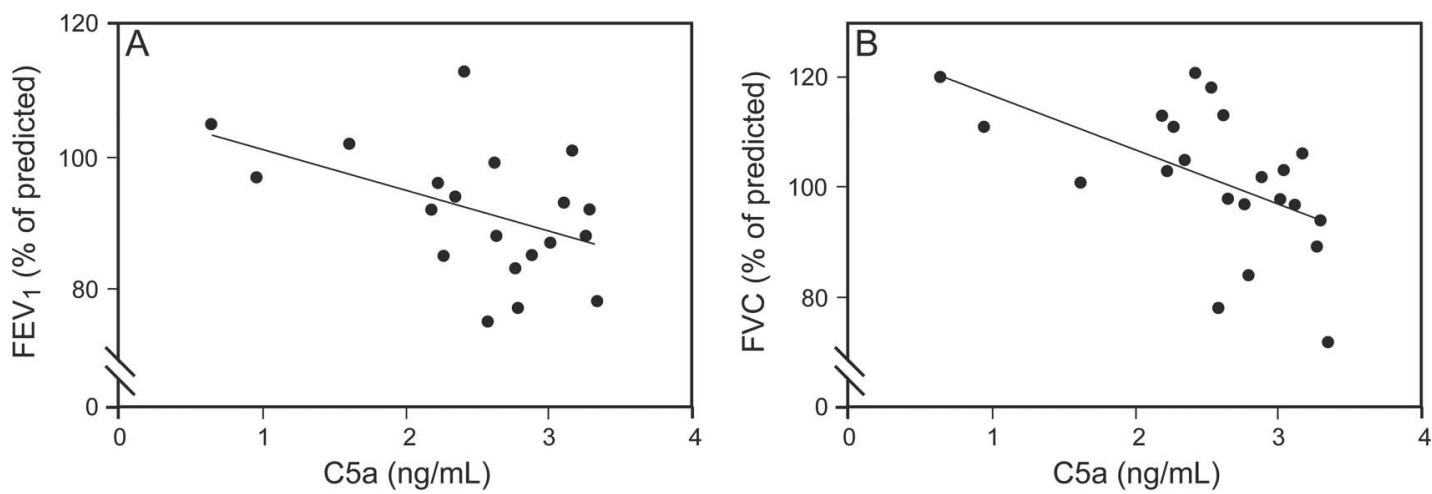

Fig. 3. Negative correlation between circulating C5a levels and $\mathrm{FEV}_{1}(\mathrm{~A})$ and $\mathrm{FVC}(\mathrm{B})$ values in pregnant women with asthma $(n=20)$.

with those carrying male fetuses, a difference that reached only the level of a trend $(P=.07)$.

\section{Discussion}

The complement system plays an important role in the development of asthma ${ }^{11,12}$; therefore, evaluation of this complex system could potentially help to better understand the disease and may even serve as a biomarker pool for asthma control. This latter possibility is especially important during pregnancy in order to maintain optimal asthma control and thus prevent unwanted effects of the disease on pregnancy outcomes. ${ }^{6}$ For the first time, in the present study, we investigated 2 major proteins of the complement cascade, C5a and complement factor $\mathrm{H}$, in pregnant subjects with asthma compared with non-pregnant subjects with asthma and with healthy pregnant and non-pregnant subjects. C5a levels were increased solely in pregnant women with asthma, and higher C5a levels implied worse lung function in these subjects with regard to both $\mathrm{FEV}_{1}$ and FVC. C5a levels were found to be associated also with airway inflammation because they correlated with $\mathrm{F}_{\mathrm{ENO}}$ levels in non-pregnant subjects. On the other hand, a pregnancy-specific elevation of regulatory complement factor $\mathrm{H}$ levels was demonstrated in both pregnant groups regardless of concomitant asthma.

The anaphylatoxin C5a, a cleaved fragment of $\mathrm{C} 5$, is one of the highly inflammatory key effector molecules of the complement system. ${ }^{25}$ In contrast, complement factor $\mathrm{H}$ is a major soluble regulator primarily of the alternative and classical pathways. ${ }^{26}$ Having homeostatic roles, a certain degree of spontaneous activation of the complement system can always be found in healthy people, indicating a controlled working of this ancient danger-sensing system in normal conditions; however, a delicate balance of activation and regulation is important to preclude normal selftissue damage. ${ }^{10,27} \mathrm{We}$ found a correlation between C5a and complement factor $\mathrm{H}$ in the healthy control population, presumably suggesting a balanced state between activation and regulation.
C5a has a dual role in asthma: During the phase of sensitization, it protects against the initiation of Th2-mediated airway inflammation, but in already established disease, it becomes highly pro-inflammatory and further enhances airway hyperreactivity. ${ }^{11,12,28} \mathrm{C} 5$ a may contribute to airway inflammation in asthma, ${ }^{11,12,28}$ which was reflected in the correlation between $\mathrm{C} 5 \mathrm{a}$ and $\mathrm{F}_{\mathrm{ENO}}$ levels in non-pregnant subjects with asthma in our study. Furthermore, inhibition of C5a improved lung function, airway hyperreactivity, and airway inflammation in animal models and in mild allergic asthma subjects. ${ }^{29,30} \mathrm{~F}_{\mathrm{ENO}}$ levels were not evaluated in the healthy pregnant group, since, according to our previous data, pregnancy itself does not have an influence on normal $\mathrm{F}_{\mathrm{ENO}}$ values. ${ }^{31}$

As a novel finding of our study, we demonstrated an asthma-induced increase in circulating C5a levels in pregnant subjects with asthma, which was not detected either in healthy pregnant women or in any other group and which was associated with impaired lung function with regard to both $\mathrm{FEV}_{1}$ and $\mathrm{FVC}$ in pregnant subjects with asthma. A limitation of our study was that lung function was not measured in healthy control groups, and therefore our results confirm a negative correlation between $\mathrm{C} 5 \mathrm{a}$ levels and $\mathrm{FEV}_{1}$ and $\mathrm{FVC}$ values only in the pregnant asthma subject group; no conclusion can be drawn regarding this issue in healthy pregnancy. Higher concentrations of complement anaphylatoxins (eg, C5a) may cause recurrent spontaneous abortion, ${ }^{20,32}$ preterm birth, ${ }^{33,34}$ and preeclampsia, ${ }^{21,22}$ whereas treatment with the $\mathrm{C} 5$ inhibitor eculizumab may have therapeutic relevance in these conditions. ${ }^{35}$ Importantly, eculizumab seems to be administrable safely in pregnancy in the long term. ${ }^{36,37}$ In our study, we found similar C5a levels in healthy pregnant and non-pregnant women and could not detect any association between C5a levels and obstetric parameters, such as fetal birthweight or gestational week at delivery; of note, these pregnancies were without complications.

Elevation of complement factor $\mathrm{H}$ in healthy pregnancy was already known earlier, ${ }^{19}$ and we confirmed this again, but here we also tested whether this pregnancy-specific 


\section{C5a and Complement Factor H With Asthma Control in Pregnancy}

elevation is present in pregnant women with asthma as well. Indeed, asthma did not suppress the elevation of complement factor $\mathrm{H}$ in our pregnant subjects compared with healthy ones, so that complement factor $\mathrm{H}$ was elevated in both pregnant groups regardless of the presence of asthma; however, it must be noted that the majority of pregnant women with asthma were ICS-treated and wellcontrolled. In addition, hormonal and physiological changes of pregnancy may differ across trimesters, which might influence our results. Nevertheless, if regulators (such as complement factor $\mathrm{H}$ ) are dysfunctional during pregnancy, excessive complement activation may lead to placental damage and preeclampsia. ${ }^{38-40}$ In our study, none of the women showed any obstetric complications in any pregnant group, which may be, at least partly, a result of well balanced complement activation.

In our previous study, only induced sputum levels of complement factor $\mathrm{H}$ were increased in asthma and were related to worse lung function, whereas plasma levels were not elevated and did not correlate with any clinical parameter. ${ }^{17}$ This latter finding was supported by the current study, because in non-pregnant subjects, we could not demonstrate any association between plasma complement factor $\mathrm{H}$ levels and asthma control determinants. However, in the subgroup of second-trimester pregnant women with asthma, complement factor $\mathrm{H}$ levels showed a trend toward a direct correlation with peak expiratory flow. This phenomenon might imply that more rigorous control of complement activation could be beneficial during the pregnancy of asthma patients; notably, a significantly large sample size evaluation would be warranted to confirm our observation. A possible reason why pregnant subjects received a somewhat lower dose of ICS is that pregnant women are less adherent in taking the prescribed ICS regularly.2,5 This may theoretically also explain why the association between complement factor $\mathrm{H}$ and peak expiratory flow was detectable only in pregnant and not in non-pregnant subjects. However, because ICS dose did not influence plasma complement factor $\mathrm{H}$ levels significantly in any of the groups, this explanation remains hypothetical.

\section{Conclusions}

According to our data, the circulating level of pro-inflammatory C5a is elevated in pregnant women with asthma and shows a relationship to impaired lung function in this patient group. On the other hand, pregnancies of both healthy and subjects with asthma increase the level of regulatory complement factor $\mathrm{H}$, which seems to be a pregnancy-specific change independent of concomitant asthma.

\section{REFERENCES}

1. Global Strategy for Asthma Management and Prevention, Global Initiative for Asthma (GINA) 2015. Available from: http://www. ginasthma.org/. Accessed September 17, 2014.

2. Charlton RA, Hutchison A, Davis KJ, de Vries CS. Asthma management in pregnancy. PLoS One 2013;8(4):e60247.

3. Demissie K, Breckenridge MB, Rhoads GG. Infant and maternal outcomes in the pregnancies of asthmatic women. Am J Respir Crit Care Med 1998;158(4):1091-1095.

4. Breton MC, Beauchesne MF, Lemière C, Rey E, Forget A, Blais L. Risk of perinatal mortality associated with asthma during pregnancy. Thorax 2009;64(2):101-106.

5. Murphy VE, Clifton VL, Gibson PG. Asthma exacerbations during pregnancy: incidence and association with adverse pregnancy outcomes. Thorax 2006;61(2):169-176.

6. Tamási L, Horváth I, Bohács A, Müller V, Losonczy G, Schatz M. Asthma in pregnancy: immunological changes and clinical management. Respir Med 2011;105(2):159-164.

7. Grindheim G, Toska K, Estensen ME, Rosseland LA. Changes in pulmonary function during pregnancy: a longitudinal cohort study. BJOG 2012;119(1):94-101.

8. Ivancsó I, Toldi G, Bohács A, Eszes N, Müller V, Rigó J Jr, et al. Relationship of circulating soluble urokinase plasminogen activator receptor (suPAR) levels to disease control in asthma and asthmatic pregnancy. PLoS One 2013;8(4):e60697.

9. Eszes N, Toldi G, Bohács A, Ivancsó I, Müller V, Rigó J Jr, et al. Relationship of circulating hyaluronic acid levels to disease control in asthma and asthmatic pregnancy. PLoS One 2014;9(4):e94678.

10. Ricklin D, Hajishengallis G, Yang K, Lambris JD. Complement: a key system for immune surveillance and homeostasis. Nat Immunol 2010;11(9):785-797.

11. Zhang X, Köhl J. A complex role for complement in allergic asthma. Expert Rev Clin Immunol 2010;6(2):269-277.

12. Laumonnier Y, Schmudde I, Köhl J. The role of complement in the diagnosis and management of allergic rhinitis and allergic asthma. Curr Allergy Asthma Rep 2011;11(2):122-130.

13. Krug N, Tschernig T, Erpenbeck VJ, Hohlfeld JM, Köhl J. Complement factors C3a and C5a are increased in bronchoalveolar lavage fluid after segmental allergen provocation in subjects with asthma. Am J Respir Crit Care Med 2001;164(10 Pt 1):1841-1843.

14. Marc MM, Korosec P, Kosnik M, Kern I, Flezar M, Suskovic S, Sorli J. Complement factors c3a, c4a, and c5a in chronic obstructive pulmonary disease and asthma. Am J Respir Cell Mol Biol 2004; 31(2):216-219.

15. Bowser C, Erstein DP, Silverberg JI, Nowakowski M, Joks R. Correlation of plasma complement split product levels with allergic respiratory disease activity and relation to allergen immunotherapy. Ann Allergy Asthma Immunol 2010;104(1):42-49.

16. Kopp A, Hebecker M, Svobodová E, Józsi M. Factor H: a complement regulator in health and disease, and a mediator of cellular interactions. Biomolecules 2012;7:2(1):46-75.

17. Weiszhár Z, Bikov A, Gálffy G, Tamási L, Ungvári I, Szalai C, et al. Elevated complement factor $\mathrm{H}$ levels in asthmatic sputa. J Clin Immunol 2013;33(2):496-505.

18. Richani K, Soto E, Romero R, Espinoza J, Chaiworapongsa T, Nien $\mathrm{JK}$, et al. Normal pregnancy is characterized by systemic activation of the complement system. J Matern Fetal Neonatal Med 2005;17(4): 239-245.

19. Derzsy Z, Prohászka Z, Rigó J Jr, Füst G, Molvarec A. Activation of the complement system in normal pregnancy and preeclampsia. Mol Immunol 2010;47(7):1500-1506.

20. Banadakoppa M, Chauhan MS, Havemann D, Balakrishnan M, Dominic JS, Yallampalli C. Spontaneous abortion is associated with el- 


\section{C5a and Complement Factor H With Asthma Control in Pregnancy}

evated systemic C5a and reduced mRNA of complement inhibitory proteins in placenta. Clin Exp Immunol 2014;177(3):743-749.

21. Denny KJ, Coulthard LG, Finnell RH, Callaway LK, Taylor SM, Woodruff TM. Elevated complement factor C5a in maternal and umbilical cord plasma in preeclampsia. J Reprod Immunol 2013; 97(2):211-216.

22. Soto E, Romero R, Richani K, Espinoza J, Chaiworapongsa T, Nien $\mathrm{JK}$, et al. Preeclampsia and pregnancies with small-for-gestational age neonates have different profiles of complement split products. J Matern Fetal Neonatal Med 2010;23(7):646-657.

23. Miller MR, Hankinson J, Brusasco V, Burgos F, Casaburi R, Coates A, et al. Standardisation of spirometry. Eur Respir J 2005;26(2):319-338.

24. American Thoracic Society, European Respiratory Society. ATS/ERS recommendations for standardized procedures for the online and offline measurement of exhaled lower respiratory nitric oxide and nasal nitric oxide. Am J Respir Crit Care Med 2005; 171(8):912-930

25. Wong EK, Kavanagh D. Anticomplement C5 therapy with eculizumab for the treatment of paroxysmal nocturnal hemoglobinuria and atypical hemolytic uremic syndrome. Transl Res 2015;165(2): 306-320.

26. Tan LA, Yu B, Sim FC, Kishore U, Sim RB. Complement activation by phospholipids: the interplay of factor $\mathrm{H}$ and $\mathrm{C} 1 \mathrm{q}$. Protein Cell 2010;1(11):1033-1049.

27. Köhl J. The role of complement in danger sensing and transmission. Immunol Res 2006;34(2):157-176.

28. Khan MA, Nicolls MR, Surguladze B, Saadoun I. Complement components as potential therapeutic targets for asthma treatment. Respir Med 2014;108(4):543-549.

29. Smith SG, Watson B, Clark G, Gauvreau GM. Eculizumab for treatment of asthma. Expert Opin Biol Ther 2012;12(4):529-537.

30. Baelder R, Fuchs B, Bautsch W, Zwirner J, Köhl J, Hoymann HG, et al. Pharmacological targeting of anaphylatoxin receptors during the effector phase of allergic asthma suppresses airway hyperresponsiveness and airway inflammation. J Immunol 2005;174(2):783-789.
31. Tamási L, Bohács A, Bikov A, Andorka C, Rigó J Jr., Losonczy G, Horváth I. Exhaled nitric oxide in pregnant healthy and asthmatic women. J Asthma 2009;46(8):786-791.

32. Lee J, Oh J, Choi E, Park I, Han C, Kim do H, et al. Differentially expressed genes implicated in unexplained recurrent spontaneous abortion. Int J Biochem Cell Biol 2007;39(12):2265-2277.

33. Lappas M, Woodruff TM, Taylor SM, Permezel M. Complement C5A regulates prolabor mediators in human placenta. Biol Reprod 2012;86(6): 190

34. Soto E, Romero R, Richani K, Yoon BH, Chaiworapongsa T, Vaisbuch E, et al. Evidence for complement activation in the amniotic fluid of women with spontaneous preterm labor and intra-amniotic infection. J Matern Fetal Neonatal Med 2009; 22(11):983-992.

35. Burwick RM, Feinberg BB. Eculizumab for the treatment of preeclampsia/HELLP syndrome. Placenta 2013;34(2):201-203.

36. Kelly R, Arnold L, Richards S, Hill A, Bomken C, Hanley J, et al The management of pregnancy in paroxysmal nocturnal haemoglobinuria on long term eculizumab. Br J Haematol 2010;149(3):446450.

37. Ardissino G, Wally Ossola M, Baffero GM, Rigotti A, Cugno M. Eculizumab for atypical hemolytic uremic syndrome in pregnancy. Obstet Gynecol 2013;122(2 Pt 2):487-489.

38. Buurma A, Cohen D, Veraar K, Schonkeren D, Claas FH, Bruijn JA, et al. Preeclampsia is characterized by placental complement dysregulation. Hypertension 2012;60(5):1332-1337.

39. Salmon JE, Heuser C, Triebwasser M, Liszewski MK, Kavanagh D, Roumenina L, et al. Mutations in complement regulatory proteins predispose to preeclampsia: a genetic analysis of the PROMISSE cohort. PLoS Med 2011;8(3):e1001013.

40. Fakhouri F, Jablonski M, Lepercq J, Blouin J, Benachi A, Hourmant $\mathrm{M}$, et al. Factor $\mathrm{H}$, membrane cofactor protein, and factor I mutations in patients with hemolysis, elevated liver enzymes, and low platelet count syndrome. Blood 2008;112(12):4542-4545. 